\title{
Industrial Sintering Response and Microstructural Characterization of Aluminum Powder Metallurgy Alloy Alumix 123
}

\author{
W. D. Judge ${ }^{1}$ D. P. Bishop ${ }^{1}$ G. J. Kipouros ${ }^{1}$
}

Received: 18 July 2017/Revised: 10 August 2017/Accepted: 11 August 2017/Published online: 22 August 2017

(C) Springer Science+Business Media, LLC and ASM International 2017

\begin{abstract}
In this work, the industrial sintering response of the commercial aluminum powder metallurgy alloy 'Alumix 123' has been examined and the resulting microstructure investigated by optical microscopy, scanning electron microscopy, energy-dispersive $\mathrm{x}$-ray spectroscopy, and x-ray diffraction. Alumix 123 is similar in composition to wrought aluminum alloy 2014 and was revealed to develop a sintered density of $92 \%$ of theoretical using standard practices for industrial sintering. Microstructural investigations proved that as a result of industrial sintering, a number of embrittling iron-containing intermetallics are developed in addition to the desirable copper-rich intermetallics. To improve the density of sintered components, procedures were developed for secondary processing by 'sizing' (repressing) in a laboratory setting. The results showed that sizing to the industry standard reduction in height of 5\% only closed a portion of open surface porosity and that higher sizing pressures should be used in applications that are sensitive to this microstructural feature.
\end{abstract}

Keywords Aluminum alloy · Powder metallurgy · Sintering $\cdot$ Sizing $\cdot$ Intermetallics $\cdot$ Alumix 123

\section{G. J. Kipouros}

georges@kipouros.ca

1 Materials Engineering, Process Engineering and Applied Science, Dalhousie University, 1360 Barrington Street, Room F201, Halifax, NS B3H 4R2, Canada

\section{Introduction}

Powder metallurgy (PM) is a diverse manufacturing technique which may be utilized to mass-produce precise and complex parts in a cost-effective and sustainable manner. To produce large amounts of small and complex components by traditional metal processing methods involving casting or forming typically requires expensive and wasteful secondary machining operations. In some instances, it is appropriate to use PM in place of traditional metal processing methods to produce net- or near-net-shape components which require little or no secondary machining operations. PM processing, however, naturally results in different metallurgical structures and residual porosity which affect the properties and performance of PM materials compared to their wrought or cast counterparts.

The production of aluminum alloys by PM begins with a powder premix composed of elemental aluminum powder, alloy addition powders, and lubricant powder [1]. The premix is subjected to uniaxial die compaction to form a green compact of near-net-shape, which is then sintered under dry nitrogen. A de-lubrication step is incorporated into the sinter cycle prior to sintering to remove the solid lubricant which is necessary for die compaction. Most aluminum PM alloys are 'liquid phase sintered' to help disrupt the aluminum oxide layer on particles and enhance densification, but this also causes more dimensional distortion as compared to solid-state sintering [2]. To remedy this, aluminum PM alloys are usually 'sized' to improve dimensional tolerances by repressing in a die after sintering [3].

The most prolific application for PM aluminum is in the automotive industry, where PM aluminum has been used to manufacture an estimated 200 million camshaft bearing caps for consumer automobiles since production began in 
the early 1990s [3]. Here, the PM alloy of choice is an aluminum-copper-magnesium-silicon alloy based on wrought aluminum alloy 2014 [4]. The 2014-based PM alloy system is now standardized by the 'AC-2014' designation set forth in ASTM Standard B595 and is presently offered commercially under the trade name 'Alumix 123.'

The sintering response of Alumix 123 has been studied in the laboratory [5-8] where liquid phase sintering mechanisms have been elucidated and sintering procedures have been developed to illicit optimum mechanical properties on the laboratory scale. However, there is less work available in the open literature on the industrial sintering response and microstructural characterization of Alumix 123. In the industrial furnace, aluminum PM parts are sintered under more robust conditions involving faster heating rates and shorter sinter times [9] - as is the nature of commercial PM manufacturing which allows for high productivity and good economy.

In this work, the industrial sintering response of the commercial aluminum PM alloy Alumix 123 has been studied alongside a series of laboratory trials developed to evaluate the response to compaction pressure and sizing, and the resultant microstructure of Alumix 123 is then thoroughly characterized [10].

\section{Experimental}

\section{Materials}

Alumix 123 was obtained as a powder premix from ECKA Granules Germany GmbH (Fürth, Bavaria, Germany). The premix contained all the necessary alloy components, including 1.5 wt.\% 'Licowax C' (ethylene bisstearamide) solid lubricant and was delivered as a 'press-ready' product which was premixed at the plant of manufacture. The premix was certified to quality control standards by the manufacturer for particle size distribution, apparent density, flowability, and chemical composition. Its chemical composition was also analyzed by inductively coupled plasma optical emission spectrometry (ICP-OES) and is shown in Table 1. Its cumulative particle size distribution was also verified by laser particle size analysis and the $D_{10}$, $D_{50}$, and $D_{90}$ were determined to be $27.1,95.4$, and $196 \mu \mathrm{m}$, respectively.

\section{PM Processing}

Green compacts were formed by uniaxially compacting $2.5 \mathrm{~g}$ of powder premix in a 15 -mm-diameter tungsten carbide floating die assembly. Compaction pressure was applied using a load frame with a $1 \mathrm{MN}$ capacity. Specimens sintered industrially were all compacted at $300 \mathrm{MPa}$, while specimens sintered in a laboratory setting were compacted at increments of $100 \mathrm{MPa}$ from 100 to $600 \mathrm{MPa}$ to study the effect on processing response.

To study the industrial sintering response, green compacts were sintered at GKN Sinter Metals (Conover, NC, USA) under a dry nitrogen atmosphere in a continuous wire mesh belt conveyor furnace. The green compacts were placed on a shallow tray which was then placed on the wire mesh belt conveyor among industrial product. GKN Sinter Metals regularly sinters Alumix 123 components in high volume, and standard operating procedures were employed in sintering the material for this work.

Industrially sintered specimens were sized using the same load frame for powder compaction, however in a larger, 30-mm-diameter, die assembly in order to accommodate the dimensional changes that occurred during sintering. Immediately prior to sizing, specimens were carefully deburred by hand against $\mathrm{SiC}$ paper and fully submersed in sizing fluid provided by GKN Sinter Metals. Sizing pressures are reported with respect to the original 15-mm-diameter compacts.

A portion of specimens were sintered in a laboratory setting using a 3-zone horizontal tube furnace. Prior to sintering, the furnace was evacuated to $<7 \mathrm{~Pa}$ and purged with nitrogen twice. The sinter cycle consisted of a 30-min de-lubrication stage at $400{ }^{\circ} \mathrm{C}$ followed by a 20 -min sinter at $595^{\circ} \mathrm{C}$. The entire sinter cycle took place under an atmosphere of high-purity flowing nitrogen (>99.999\% reported purity). After sintering, specimens were gas

Table 1 Chemical analysis of Alumix 123 by ICP-OES (wt.\%)

\begin{tabular}{lllllllll}
\hline Composition & $\mathrm{Al}$ & $\mathrm{Cu}$ & $\mathrm{Mg}$ & $\mathrm{Si}$ & $\mathrm{Fe}$ & $\mathrm{Mn}$ & Others (each) & Others (total) \\
\hline Nominal $^{\mathrm{a}, \mathrm{b}}$ & Balance & $4.30-4.70$ & $0.40-0.60$ & $0.50-0.80$ & $\ldots$ & $\ldots$ & $\ldots$ & $\ldots$ \\
Analyzed $^{\mathrm{c}}$ & Balance & 4.57 & 0.52 & 0.80 & 0.11 & $<0.01$ & $\ldots$ & $\ldots$ \\
\hline
\end{tabular}

a Nominal composition according to manufacturer's specification

b Plus 1.40-1.60 wt.\% lubricant

c Analysis was performed on a sintered compact

${ }^{\mathrm{d}} \mathrm{Ca}$ : 0.03; Ga: 0.01; K: <0.01; Na: 0.02; Ni: 0.01; P: 0.03; Pb: 0.01; S: 0.02; Sn: 0.02; V: 0.01; Zn: 0.05 
quenched in a water-cooled jacket and remained under flowing nitrogen until their temperature reached $100{ }^{\circ} \mathrm{C}$. Throughout the entire sinter cycle, the temperature in the immediate vicinity of the compacts was measured with a thermocouple connected to a digital thermometer. The average quench rate was about $0.95{ }^{\circ} \mathrm{C} \mathrm{s}^{-1}$ from the sintering temperature to $300{ }^{\circ} \mathrm{C}$, while a total of about $26 \mathrm{~min}$ elapsed after quenching before the temperature reached $100{ }^{\circ} \mathrm{C}$.

\section{PM Processing Response}

Green and sintered densities were measured in accordance with Metal Powder Industries Federation (MPIF) Standard 42. The method is based on hydrostatic weighing where specimens were first weighed in air and then subsequently in deionized water. Prior to hydrostatic weighing, sintered specimens were sealed by vacuum oil impregnation at room temperature. Green compacts were effectively sealed by the solid lubricant present in the premix so no oil impregnation was necessary. The theoretical density of Alumix 123 was calculated from its nominal composition as $2.777 \mathrm{~g} \mathrm{~cm}^{-3}$ using equations provided by The Aluminum Association. Dimensional and mass changes after sintering and dimensional changes after sizing were evaluated with calipers, micrometers, and scales through standard PM practices.

\section{Microstructural Characterization}

Specimens were prepared for microscopy using standard metallographic procedures which included abrasion on successively finer grits of wet $\mathrm{SiC}$ paper followed by polishing using successively finer oil-based diamond suspensions (to $1 \mu \mathrm{m}$ ), cleaning, and drying.

Optical micrographs were captured using a light microscope and digital camera. Some specimens were etched using a solution of $2 \mathrm{~g} \mathrm{NaOH}, 5 \mathrm{~g} \mathrm{NaF}, 93 \mathrm{~mL} \mathrm{H}_{2} \mathrm{O}$ to reveal their microstructure. To examine cross sections in the optical microscope, some specimens were mounted by vacuum impregnation with a self-curing resin, sectioned, and polished.

Electron micrographs were captured using a cold field emission scanning electron microscope. The scanning electron microscope contained an integrated silicon drift detector for energy-dispersive $\mathrm{x}$-ray spectroscopy analyses. For imaging, the scanning electron microscope was operated with a $10 \mathrm{kV}$ accelerating voltage and $20 \mu \mathrm{A}$ emission current, while for energy-dispersive x-ray spectroscopy analyses, a $20 \mathrm{kV}$ accelerating voltage and $10 \mu \mathrm{A}$ emission current were used. During imaging, the scanning electron microscope was operated in a 'mixed detector mode' where signals were collected and mixed from two secondary electron detectors: an upper 'through-the-lens' detector located above the objective lens and a lower EverhartThornley detector located inside the specimen chamber. The lower detector also collected some amount of backscattered electrons which allowed atomic contrast to be distinguished. To examine the powder premix in the scanning electron microscope, it was mounted to a pin stub using silver chloride paste.

$\mathrm{X}$-ray diffraction (XRD) patterns were collected using $\mathrm{CuK}_{\alpha 1}$ radiation, a tube voltage of $40 \mathrm{kV}$, and a tube current of $40 \mathrm{~mA}$. The powder diffraction files (PDFs) used to identify phases are provided with the XRD traces.

\section{Results and Discussion}

\section{PM Processing Response}

The effect of compaction pressure on the green and sintered density of Alumix 123 is shown in Fig. 1 and on the dimensional and mass change after sintering in Fig. 2. Some specimens were prepared using a variety of compaction pressures and sintered in a laboratory setting to study the effect of this parameter on PM processing response. The highest practical green and sintered densities were achieved with a compaction pressure of $300 \mathrm{MPa}$ (Fig. 1). Higher compaction pressures led to no significant improvements in green or sintered density and only served to increase die wear and induced more dimensional distortion during sintering (Fig. 2). With this information, all specimens sintered in an industrial setting were prepared using a powder compaction pressure of $300 \mathrm{MPa}$.

Alumix 123 did not significantly densify during sintering as shown in Fig. 1; the highest sintered density was for industrially sintered specimens which reached $92 \%$ theoretical density. This result is in agreement with other laboratory investigations, which found that extending the

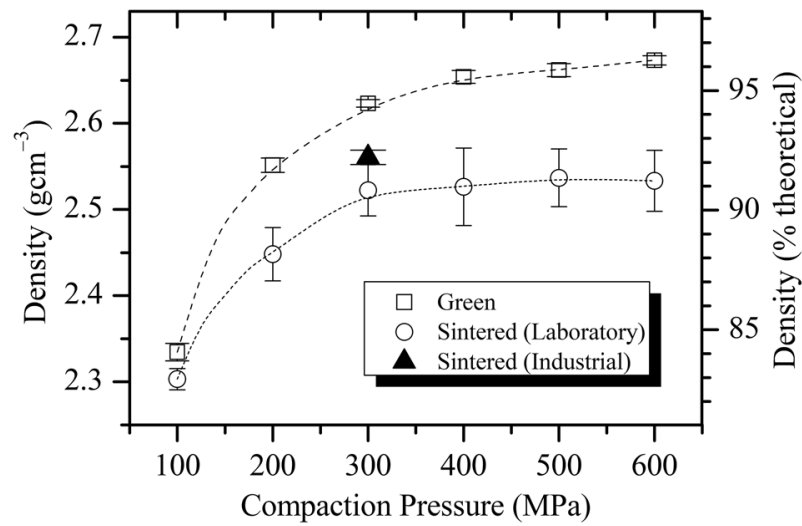

Fig. 1 Green and sintered density of Alumix 123 as a function of compaction pressure 
isothermal sintering time or increasing the sintering temperature did not significantly increase the sintered density of Alumix 123 [6-8]. Although the low sintered density may seem unattractive toward mechanical properties, the presence of residual surface porosity is beneficial in oilimpregnated parts where it acts as a reservoir for oil, creating a 'self-lubricating' effect which improves wear resistance [3]. The change in mass for all specimens after sintering matched closely to the nominally $1.5 \mathrm{wt} . \%$ solid lubricant present in the green compacts (Fig. 2).

The low sintered density of Alumix 123 may be interpreted in terms of the swelling of compacts as a result of sintering (Fig. 2). Laboratory studies on the sintering mechanisms of Alumix 123 have attributed the swelling to the formation and disappearance of transient liquid phases caused by partial melting or contact melting between components of the premix [8]. In the present work, it was observed that the swelling of compacts occurred principally along the axis of uniaxial compaction (the height dimension) (Fig. 2). The large volume change in the height direction was postulated to be related to the diffusion of alloying elements from the liquid phase into aluminum grains.

In the green compacts, the contact area between alloy powders and the base elemental aluminum powder was postulated to have been larger along the radial direction (axis perpendicular to uniaxial compaction) than in the axial direction (axis of uniaxial compaction). This was thought to arise from the well-known phenomenon that during uniaxial powder compaction in a rigid die, the stress experienced by the powder in the axial direction is much greater than what is experienced in the radial direction [11]. In the present case, it is possible the powder premix also experienced more strain in the axial direction, and, therefore, inter-particle contacts exhibited a slight tendency toward aligning along the radial axis during compaction. Since liquid phases tend to form at and spread along the

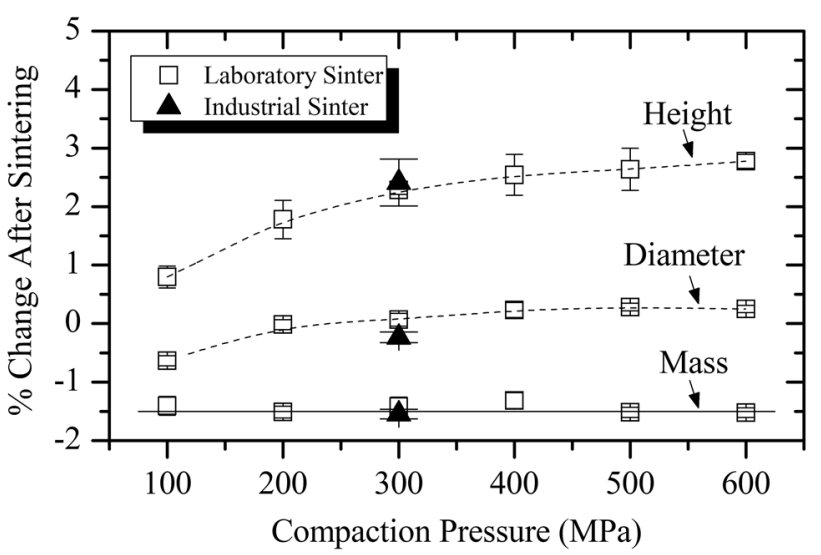

Fig. 2 Sinter-induced dimensional and mass changes measured for green compacts of Alumix 123 as functions of compaction pressure contact areas between different particles, they may have preferentially formed and spread in the radial direction during sintering of Alumix 123. The diffusion of alloy additions from the liquid phase into aluminum grains would then tend to occur more in the axial direction because this is where more aluminum grains are located relative to the liquid phase. Since the diffusion of alloying elements into aluminum grains is responsible for volume changes during sintering [8], this would explain the tendency for greater volume change of Alumix 123 in the axial direction (Fig. 2).

This mechanism is supported by aluminum-copper pressed wire model experiments where a pure copper wire was uniaxially compacted while surrounded by many pure aluminum wires [12]. Before compaction, the wires were oriented lengthwise along the radial direction (axis perpendicular to uniaxial pressing). During sintering, the aluminum-copper eutectic liquid phase penetrated rapidly in the radial direction but caused a larger swelling in the axial direction. The larger volume change in the axial direction was attributed to the preferential diffusion of copper from the liquid phase into aluminum in this direction [12]. To verify if this is the situation for Alumix 123, concurrent metallographic and dilatometric experiments should be performed throughout the sinter cycle, although this would prove difficult in an industrial setting.

The effect of sizing pressure on the reduction in height of industrially sintered Alumix 123 specimens is shown in Fig. 3. Plastic deformation was achieved at relatively low sizing pressures and was probably facilitated by the low sintered density which could easily accommodate some consolidation. Reductions in height of 5, 10, and $15 \%$ were achieved with sizing pressures of 310,390 , and $460 \mathrm{MPa}$, respectively. In a typical 'press-sinter-size' commercial setting, sizing may involve a reduction in height up to about 5\% [13]; however, the so-called powder forged

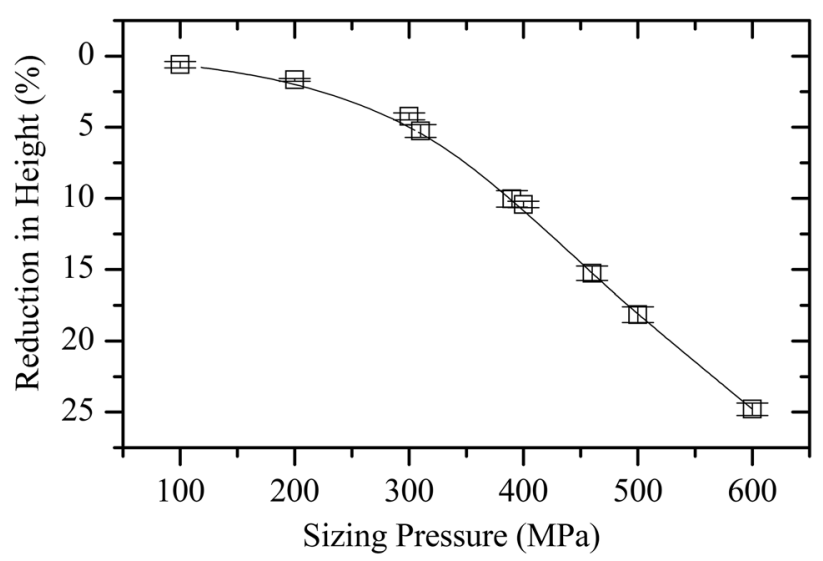

Fig. 3 Sizing curve for industrially sintered Alumix 123 specimens. All green compacts were initially prepared using a powder compaction pressure of $300 \mathrm{MPa}$ 


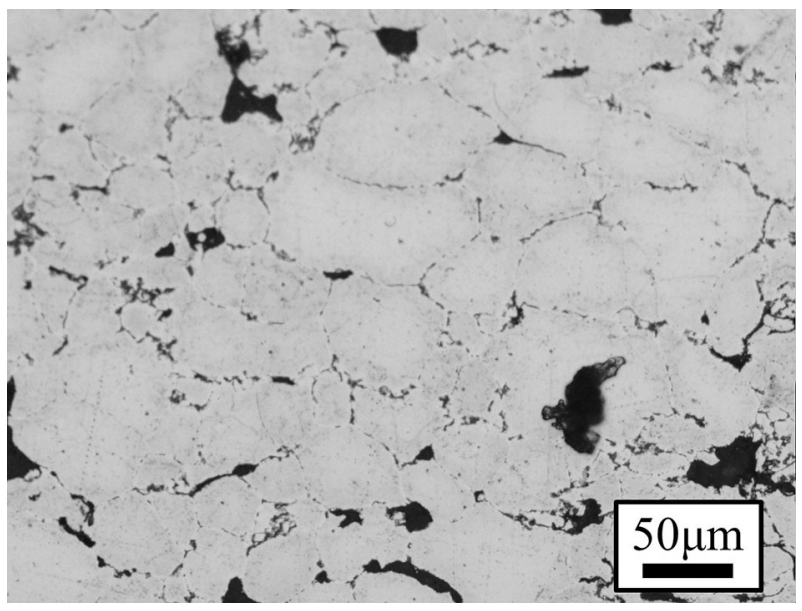

Fig. 4 Optical micrograph of industrially sintered Alumix 123 (etched) showing an equiaxed grain structure with intermetallics predominantly located along grain boundaries. The black intergranular regions are pores

alloys may utilize as much as 50\% reduction in height [14]. It should be noted that the sizing operation here was analogous to open die forging in that there were no restrictions on specimen deformation in the lateral direction.

\section{Microstructural Characterization}

Optical microscopy was performed on industrially sintered Alumix 123 and revealed an equiaxed grain structure with intermetallics distributed predominantly along grain boundaries (Fig. 4). The low sintered density of Alumix 123 was apparent by the relatively large amount of residual porosity (Fig. 4). The location of intermetallics along grain boundaries was expected as Alumix 123 is a liquid phase sintered alloy $[6-8,15]$. Throughout the duration of sintering, a persistent liquid phase was present in between aluminum grains which formed intermetallics upon solidification or decomposition during cooling.

The morphology of the intermetallics was more apparent in scanning electron microscope analyses, where different intermetallics were noted by their varying atomic contrast (Fig. 5). Scanning electron microscope images were comprised of signals collected from two secondary electron detectors; the 'lower' detector is located inside the specimen chamber and also collects some amount of backscattered electrons which allowed atomic contrast to be resolved. Energy-dispersive x-ray spectroscopy analyses showed the intermetallics with a brighter atomic contrast contained more copper compared to those with a darker atomic contrast which contained significant amounts of iron-an impurity from the base aluminum powder which segregated in the liquid phase during sintering [16]. Systematic scanning electron microscope and energy-

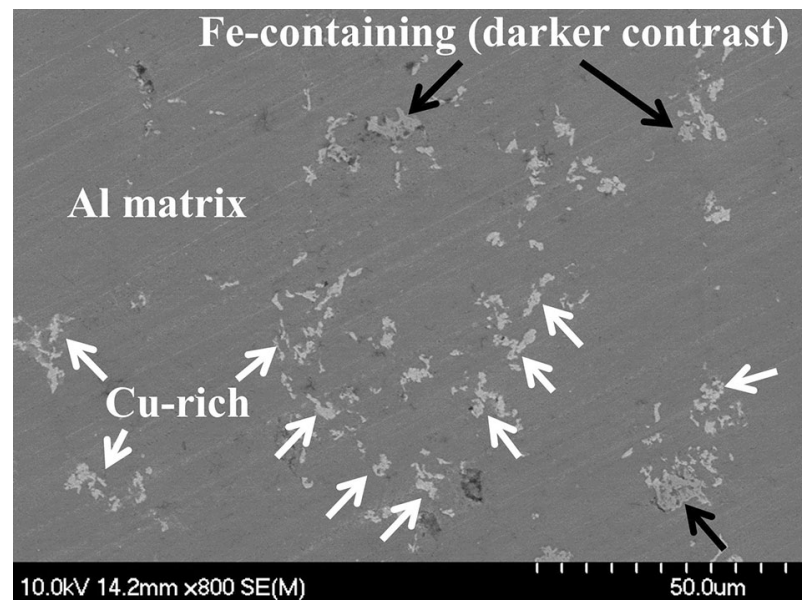

Fig. 5 Scanning electron microscope micrograph of industrially sintered Alumix 123 showing copper-rich intermetallics of lighter atomic contrast (white arrows) and iron-containing intermetallics of darker atomic contrast (black arrows)

dispersive x-ray spectroscopy analyses showed there were predominantly three distinct types of intermetallics in Alumix 123 (Fig. 6; Table 2).

The most frequent intermetallic was the copper-rich intergranular phase (Fig. 6a), which, from energy-dispersive $\mathrm{x}$-ray spectroscopy analyses (Table 2), contained less copper than would be expected for $\theta$-phase $\left(\mathrm{CuAl}_{2}\right)$ and, additionally, contained magnesium and silicon in amounts beyond what would be expected for $\theta$-phase in solid-state equilibrium [17]. There was, however, evidence of $\theta$-phase in the XRD trace of Alumix 123 (Fig. 7). The copper-rich intergranular phase was believed to be $\theta$-phase, although perhaps not in strict thermodynamic equilibrium as a result of the non-equilibrium gas quench at the conclusion of the sinter cycle.

The second most frequent intermetallic was the ironcontaining intergranular phase (Fig. 6b), which was more rounded and compact than the copper-rich intergranular phase and, from energy-dispersive $\mathrm{x}$-ray spectroscopy analyses, contained predominantly aluminum, iron, silicon, and copper (Table 2). The morphology and composition of the iron-containing intergranular phase somewhat matched the $\alpha$-AlFeSi phase $\left(\mathrm{Fe}_{2} \mathrm{SiAl}_{8}\right)$ which is typically present as a Chinese script [17] - other ternary $\mathrm{Al}-\mathrm{Fe}-\mathrm{Si}$ or $\mathrm{Al}-\mathrm{Cu}-$ Fe phases typically form platelets or needles. This phase probably solidified from the persistent liquid phase under conditions far from equilibrium as no aluminum-rich quaternary $\mathrm{Al}-\mathrm{Fe}-\mathrm{Si}-\mathrm{Cu}$ phase exists under equilibrium conditions, and the solid solubility of copper in $\alpha$-AlFeSi is less than $1 \mathrm{wt} . \%$ [17]. Due to the relatively small concentration present, there was no indication of any ironcontaining phases in the XRD trace of Alumix 123 (Fig. 7), and as energy-dispersive $\mathrm{X}$-ray spectroscopy analyses were 

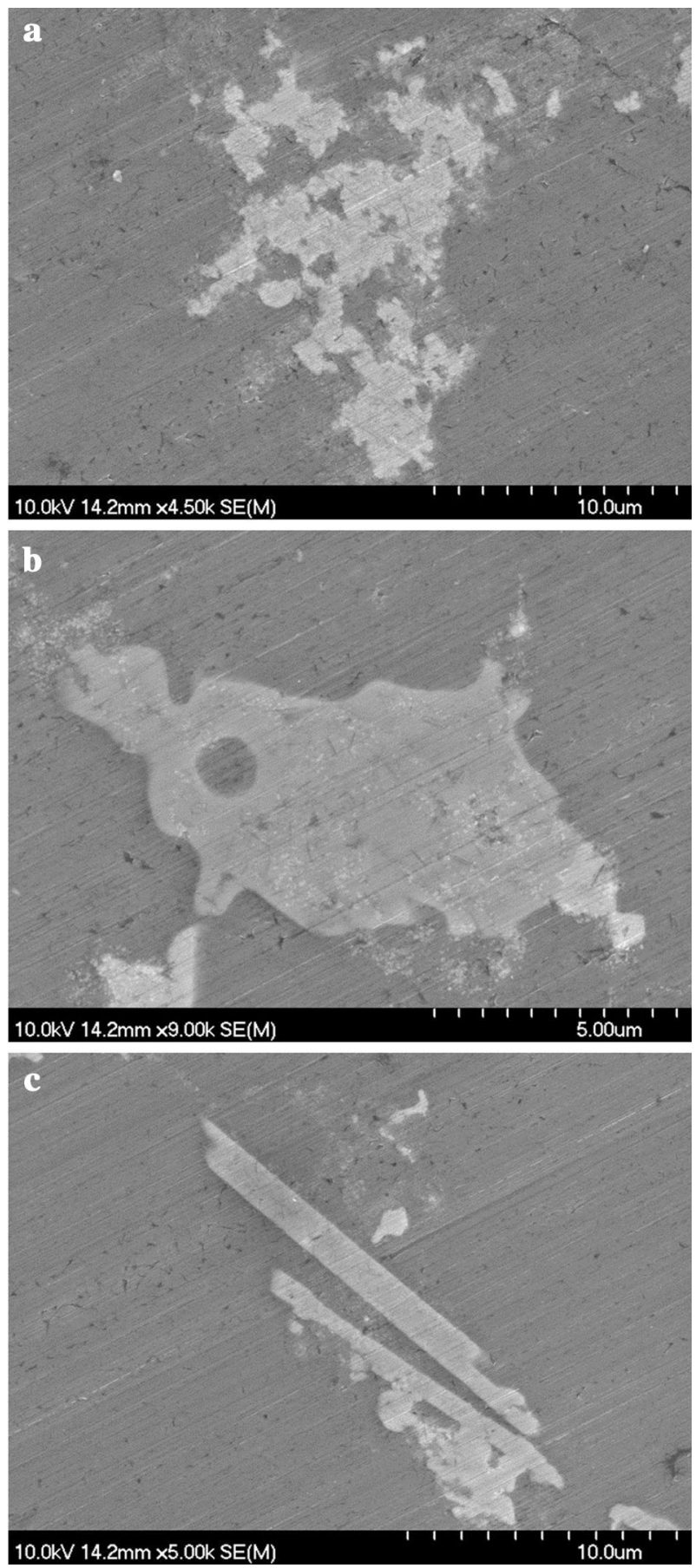

Fig. 6 Scanning electron microscope micrographs of intermetallic constituents in industrially sintered Alumix 123: (a) copper-rich intergranular phase; (b) iron-containing intergranular phase; (c) ironcontaining needle-like phase

only semiquantitative, the presence of $\alpha$-AlFeSi could not be confirmed.

The least frequent intermetallic was the iron-containing needle-like phase (Fig. 6c), which had a morphology and composition, from energy-dispersive $\mathrm{x}$-ray spectroscopy analyses (Table 2), closely matching that of $\beta(\mathrm{FeCu})$ phase
Table 2 Average energy dispersive x-ray spectroscopy analyses of major phases in industrially sintered Alumix 123 (wt.\%)

\begin{tabular}{llllll}
\hline Phase & $\mathrm{Al}$ & $\mathrm{Cu}$ & $\mathrm{Mg}$ & $\mathrm{Si}$ & $\mathrm{Fe}$ \\
\hline Matrix & 94.3 & 4.9 & 0.2 & 0.6 & $\ldots$ \\
Cu-rich intergranular $^{\mathrm{a}}$ & 57.0 & 40.1 & 2.0 & 0.9 & $\ldots$ \\
Fe-containing intergranular $^{\mathrm{b}}$ & 49.4 & 13.5 & 1.3 & 6.7 & 29.1 \\
Fe-containing needles $^{\mathrm{c}}$ & 48.2 & 34.6 & $\ldots$ & 0.7 & 16.5 \\
\hline
\end{tabular}

${ }^{\text {a }} \mathrm{CuAl}_{2}$ formula: $\mathrm{Al}: 45.9 ; \mathrm{Cu}: 54.1$

b $\mathrm{Fe}_{2} \mathrm{SiAl}_{8}$ formula: Al: 60.6; Fe: 31.6; Si: 7.8

${ }^{c} \mathrm{Cu}_{2} \mathrm{FeAl}_{7}$ formula: $\mathrm{Al}$ : 46.9; $\mathrm{Cu}: 36.9$; Fe: 16.2
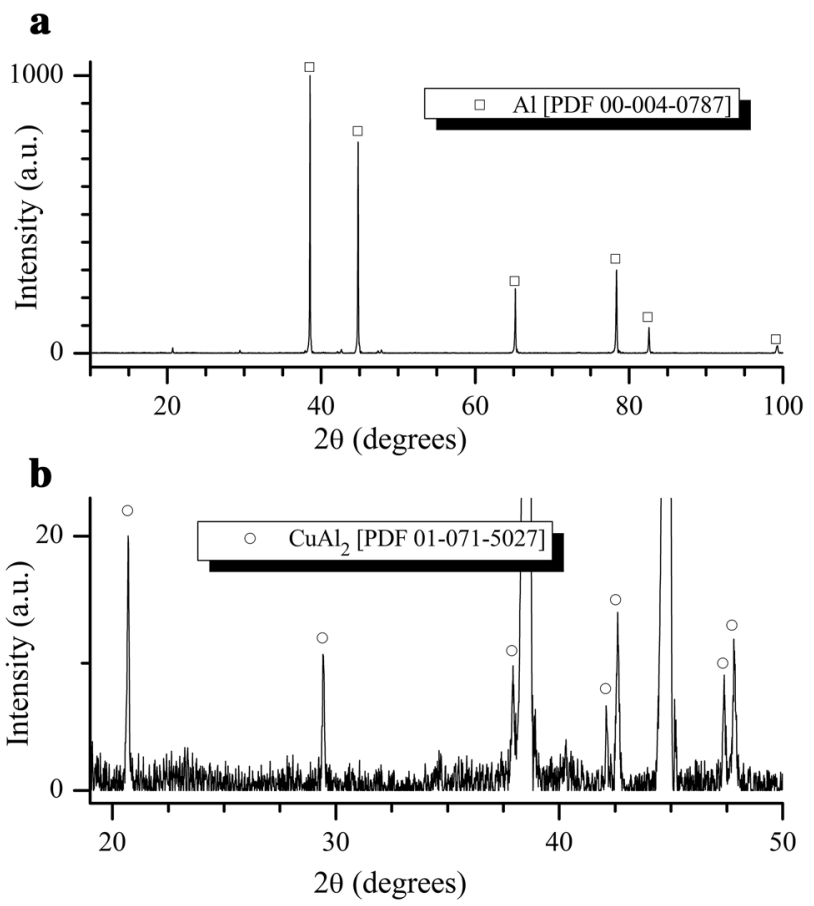

Fig. 7 XRD trace of industrially sintered Alumix 123 (polished): (a) full scan; (b) close-up of smaller peaks

$\left(\mathrm{Cu}_{2} \mathrm{FeAl}_{7}\right)$ [17]. Their marked morphological differences compared to the other types of intermetallics and their seemingly definite $\beta(\mathrm{FeCu})$ composition implied the ironcontaining needle-like phase tended more toward solidstate equilibrium than the other types of intermetallics. This phase may have formed during sintering in areas which were isolated from magnesium and silicon, where the base elemental aluminum powder was originally in contact with only elemental copper powder and, during sintering, given sufficient time to accumulate enough iron impurities in the liquid phase to precipitate $\beta(\mathrm{FeCu})$. Due to the small concentration present, there was no indication of any iron-containing phases, in the XRD trace of Alumix 123 (Fig. 7); however, based on scanning electron microscope and energy-dispersive $\mathrm{x}$-ray spectroscopy analyses, 
Fig. 8 Optical micrographs of cross-sectional microstructure of industrially sintered Alumix 123 specimens (etched): (a) assintered; and sized to a reduction in height of (b) 5\%; (c) $10 \%$; and (d) $15 \%$. The black intergranular regions are pores
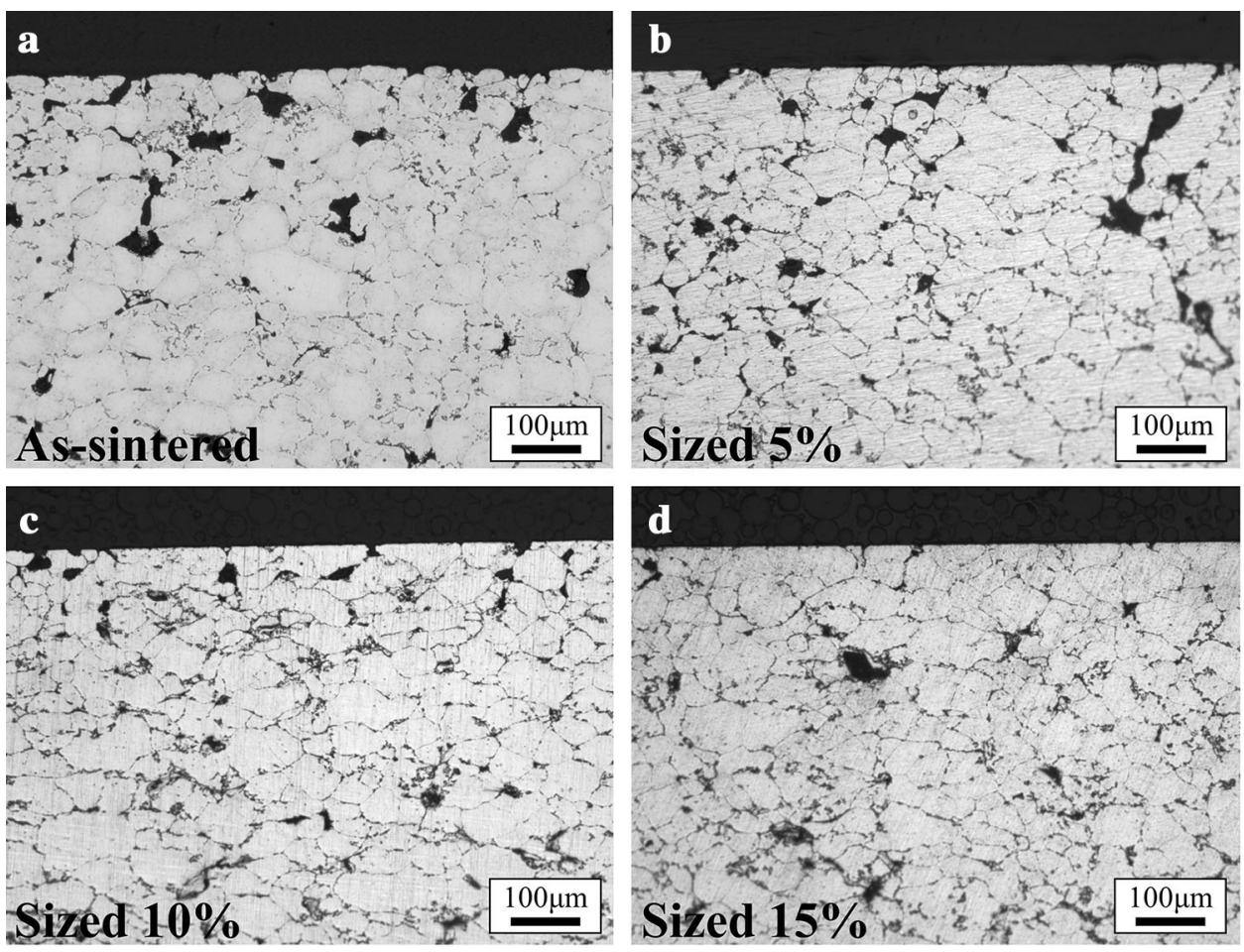

the iron-containing needle-like phase was believed to be $\beta(\mathrm{FeCu})$.

The matrix aluminum grains were found by energydispersive $\mathrm{x}$-ray spectroscopy analyses (Table 2), to contain copper, magnesium, and silicon in amounts which may be related to their solubilities in solid aluminum metal at the isothermal sintering temperature [17]. The gas quench at the conclusion of the sinter cycle is rapid enough to create a supersaturated solid solution at room temperature which is responsible for post-sinter hardening [18]. Secondary operations for Alumix 123 involving mechanical processing, such as sizing, may be affected by the postsinter hardening. On the industrial scale, it is important to conduct these operations with consideration to post-sinter hardening to facilitate working and prevent cracking.

The effect of sizing on the microstructure of Alumix 123 is shown in Fig. 8, where optical micrographs of the crosssectional microstructure near the surface of specimens are presented. It was clearly observed that the sizing operation increased the bulk density of Alumix 123, with higher sizing pressures presenting more densification (Fig. 8). Of equal or greater importance, however, was the reduction and closure of residual open surface porosity in Alumix 123 through sizing (Fig. 8), which has a particularly acute effect on critical material properties such as fatigue and corrosion resistance. Of course, with sizing, the surface of Alumix 123 became more planar as it accommodated the profile of the flat die face during deformation. It appeared that sizing to a standard reduction in height of $5 \%$ achieved some amount of densification and reduction in open surface porosity; however, if surface porosity is of special concern, sizing to a more significant reduction in height may be recommended.

\section{Conclusions}

This work investigated the industrial sintering response of Alumix 123 and characterized the resulting microstructure by optical microscopy, scanning electron microscopy, energy-dispersive x-ray spectroscopy, and XRD analyses. Additionally, the response to powder compaction and secondary processing by 'sizing' was investigated in a laboratory setting.

The results showed that the standard practice for industrial sintering Alumix 123 achieved a sintered density of $92 \%$ of theoretical. The low sintered density was confirmed in laboratory trials but was not believed to be the result of incomplete sintering. Rather, Alumix 123 compacts swelled during sintering, probably the result of volume changes as alloy additions diffused from the liquid phase into aluminum grains. To improve the density of industrial components, a sizing curve was developed for Alumix 123 which showed modest repressing pressures are capable of densifying sintered components.

The microstructure of industrially sintered Alumix 123 was characterized by an equiaxed aluminum grain structure with intermetallics primarily located along grain 
boundaries. Investigation proved that in addition to the desirable copper-containing intermetallics, a number of detrimental iron-containing intermetallics form as iron impurities report to the liquid phase during sintering. Analyses of sized compacts showed that sizing to the industry standard reduction in height of $5 \%$ closed some surface and internal porosity but did not fully densify Alumix 123. When surface porosity is of greater concern, higher sizing pressures are recommended.

Acknowledgments The authors gratefully acknowledge the Natural Sciences and Engineering Research Council of Canada (NSERC) and AUTO21 Network of Centers of Excellence for providing financial support during this work. The authors would also like to thank the Minerals Engineering Centre (MEC) at Dalhousie University for chemical and particle size analyses, the Institute for Research in Materials (IRM) at Dalhousie University for use of the scanning electron microscope/energy-dispersive $\mathrm{x}$-ray spectroscopy system, ECKA Granules for supply of the PM premix, and GKN Sinter Metals for sintering the PM material.

\section{References}

1. E.M. Daver, W.J. Ullrich, K.B. Patel, Aluminum P/M partsmaterials, production and properties. Key Eng. Mater. 29-31, 401-428 (1989)

2. G.B. Schaffer, T.B. Sercombe, R.N. Lumley, Liquid phase sintering of aluminium alloys. Mater. Chem. Phys. 67, 85-91 (2001)

3. C. Lall, D.P. Bishop, Conventional powder metallurgy aluminum alloys, in ASM Handbook Volume 7: Powder Metallurgy, ed. by P.K. Samal, J.W. Newkirk (ASM International, Materials Park, 2015), pp. 581-590

4. J.E. Foss, D. DeFranco, The Northstar Cam Bearing Caps: A New Application for Aluminum P/M, Society of Automotive Engineers, Warrendale, 1994, Report No. 940429

5. W. Kehl, M. Bugajska, H.F. Fischmeister, Internal or die wall lubrication for compaction of $\mathrm{Al}$ powders? Powder Metall. 26, 221-227 (1983)
6. J.M. Martin, F. Castro, Liquid phase sintering of P/M aluminium alloys: effect of processing conditions. J. Mater. Process. Technol. 143-144, 814-821 (2003)

7. M.L. Delgado, E.M. Ruiz-Navas, E. Gordo, J.M. Torralba, Enhancement of liquid phase sintering through $\mathrm{Al}-\mathrm{Si}$ additions to Al-Cu systems. J. Mater. Process. Technol. 162-163, 280-285 (2005)

8. J.M. Martin, F. Castro, Sintering response \& microstructural evolution of an $\mathrm{Al}-\mathrm{Cu}-\mathrm{Mg}-\mathrm{Si}$ premix. Int. J. Powder Metall. 43, 59-69 (2007)

9. D.P. Bishop, B. Hofmann, K.R. Couchman, Properties and attributes of commercially available AC2014-type aluminum P/M alloys. in Advances in Powder Metallurgy and Particulate Materials, pp. 87-100 (2000)

10. W.D. Judge, Corrosion Behaviour of Alumix 123 P/M Alloy and AA2014-T6 in $3.5 \mathrm{wt} \% \mathrm{NaCl}$, M.A.Sc. Thesis, Dalhousie University, Halifax, 2015

11. W.M. Long, Radial pressures in powder compaction. Powder Metall. 3, 73-86 (1960)

12. H. Mitani, H. Nagai, On the sintering process of Al-Cu binary mixed powder compacts. J. Jpn. Soc. Powder Powder Metall. 20, 178-183 (1973)

13. C.D. Boland, D.P. Bishop, R.L. Hexemer Jr., I.W. Donaldson, Development of an aluminum PM alloy for "press-sinter-size" technology. Int. J. Powder Metall. 47, 39-48 (2011)

14. K.E. Buchovecky, A.L. Hurst, Fabrication and properties of coldformed aluminum P/M parts. Mod. Dev. Powder Metall. 8, 189-207 (1974)

15. J.H. Dudas, R.H. Stevens, B.K. Gildersleeve, Metallography and structure interpretation of aluminum P/M parts. Int. J. Powder Metall. Powder Technol. 10, 285-293 (1974)

16. W.A.G. McPhee, G.B. Schaffer, J. Drennan, The effect of iron on liquid film migration and sintering of an $\mathrm{Al}-\mathrm{Cu}-\mathrm{Mg}$ alloy. Acta Mater. 51, 3701-3712 (2003)

17. L.F. Mondolfo, Aluminum alloys: structure and properties (Butterworths, London, 1976)

18. D.P. Bishop, R.L. McNally Jr., T.E. Geiman, Metallurgical considerations in the manufacturer and development of aluminum $\mathrm{P} / \mathrm{M}$ camshaft bearing caps, in Powder Metallurgy Aluminum and Light Alloys for Automotive Applications, ed. by W.F. Jandeska, R.A. Chernenkoff (MPIF, Princeton, 2000), pp. 177-185 